RASĀYAN J. Chem.

Vol. 13 | No. 1 |439 - 447| January - March | 2020 ISSN: 0974-1496 | e-ISSN: 0976-0083 | CODEN: RJCABP http://www.rasayanjournal.com http://www.rasayanjournal.co.in

\title{
POROSITY EFFECT OF Ag DOPED ZnO NANOCRYSTALLITES
}

\author{
M. Giruba ${ }^{1, *}$, J. Christina Rhoda ${ }^{1}$, S. Chellammal ${ }^{1}$ and K. Ravichandran ${ }^{2}$ \\ ${ }^{1}$ Department of Physics, Dr. M. G. R. Educational and Research Institute University, Advanced \\ Science Research and Development Center, Adayalampattu, \\ Chennai-600095, Tamilnadu, India. \\ ${ }^{2}$ Department of Nuclear Physics, University of Madras, Guindy Campus, Chennai-95, India. \\ *E-mail: giruba91@gmail.com
}

\begin{abstract}
The hexagonal structure of zinc oxide $(\mathrm{ZnO})$ and silver-doped zinc oxide $(\mathrm{Ag}: \mathrm{ZnO})$ nanocrystallites at room temperature was prepared using the Co-Precipitation process. Capping agent Glycerol was used to synthesize nanocrystallites. The Structural characterization such as Powder X-ray Diffraction (XRD), Scanning Electron Microscope (SEM), and Energy Dispersive X-ray Spectroscopy (EDS) was performed. The De-bye Scherer formula can be used to calculate the average size and strain also calculated using W-H graphical method. The Powder X-ray Diffraction results compared with JCPDS results. Scanning Electron Microscopy were used to study the morphological nature of the prepared sample and the Study of EDAX energy dispersive x-rays analysis used to verify the elements in the sample. The effect of silver dopant was analyzed using average size determination and strain determination methods. Excitation wavelengths of prepared samples were analyzed using UV-visible method. The porosity effect, volume fraction, hydration reaction of prepared samples were analyzed and reported.

Keywords: ZnO Nanocrystallites, Capping Agent, Co-precipitation, Porosity, Strain, Geometrical Parameter
\end{abstract}

(C) RASĀYAN. All rights reserved

\section{INTRODUCTION}

Nanotechnology (NT) is currently operating in different fields of science using various techniques on a nanometer scale through its application for materials and tools. Nanoparticles can be described as 1-100 $\mathrm{nm}$ in diameter of a single particle. Nanoparticles have become a standard material for most communications, energy storage, sensing, storing data, optics, environmental preservation, cosmetics, biological and medical applications in recent years due to their valuable optical, electrical and magnetic properties. ${ }^{1}$ According to their abundant properties in various areas such as catalysts, sensors, photoelectronic devices, highly functional and effective devices, nanosized particles of semiconductor materials have gained much attention in recent years. ${ }^{2}$ Zinc oxide [ wurtzite ] is present in the Earth's crust as zincite mineral, but mostly $\mathrm{ZnO}$ is synthetically produced for commercial purposes. ${ }^{3}$ As powders and dispersions, $\mathrm{ZnO}$ nanopowders are available. These nanoparticles have properties that trap antibacterial, antifungal, anti-corrosive, and Ultraviolet. Zinc is a Block D, period 4, while Oxide is a Block P, period 2. ${ }^{4} \mathrm{ZnO}$ is a wide band gap Semiconductor with an energy gap of $3.37 \mathrm{e} \mathrm{V}$ at room temperature. ${ }^{2}$ The zinc oxide semiconductor has several unique characteristics such as strong clarity, high mobility of electrons, wide band gap, and luminescence at room temperature. Similar properties are used in transparent electrodes in Liquid Crystal Display (LCD) and in windows and other electronic applications that save energy or heat. ${ }^{3}$ The applications of $\mathrm{ZnO}$ nanoparticles are, it is used in the manufacture of ceramics, glass, cement, rubber (e.g., car tires), lubricants, paints, ointments, adhesives, plastics, sealants, pigments, foods (source of Zn nutrient), batteries, ferrites, and fire retardants. ${ }^{4}$ Various techniques such as spray pyrolysis, thermal decomposition, molecular beam epitaxy, chemical vapor deposition and laser ablation can be used to synthesize nanomaterials or nanostructures. ${ }^{5}$ Different chemical methods used for the synthesis of $\mathrm{ZnO}$ Nanoparticles are Vapor Transport Synthesis,

Rasayan J. Chem., 13(1), 439-447(2020)

http://dx.doi.org/10.31788/RJC.2020.1315501 
RASĀYAN J. Chem.

Vol. 13 | No. 1 | 439 - 447| January - March | 2020

Hydrothermal Techniques, Precipitation method etc., Nanomaterials have been involved growing attention in recent years and their different types have been used in concrete mixtures so that develop both the mechanical properties and pore structure of the concrete. As a result, it is possible to add nano- $\mathrm{ZnO}$ particles to improve the mechanical properties of cement mortar. ${ }^{6}$ Concrete is being widely used the material in construction because of its unique structural applications such as buildings, industries, residential drainage units, water supply plants and highway infrastructure. ${ }^{7}$ In this paper, we have chosen the Precipitation method. Use of different Organic agents to control the grain size of Semiconducting nanoparticles is commonly adopted in the Chemical Precipitation techniques. ${ }^{8}$ Effects of silver-doped zinc oxide were analyzed using XRD, UV-visible spectroscopy, theoretical strain measurement and the results are investigated in this paper.

\section{EXPERIMENTAL}

\section{Materials and Methods}

The Co-Precipitation method used zinc acetate and sodium hydroxide as precursors to synthesize nanocrystalline powders of zinc oxide and silver doped zinc oxide at room temperature. The solution1 was prepared with Zinc acetate and capping agent with $100 \mathrm{ml}$ of distilled water was kept in magnetic stirrer for an hour simultaneously solution 2 with sodium hydroxide was mixed with $100 \mathrm{ml}$ distilled water and kept in another magnetic stirrer for the same 1 hour. To the first solution, second solution was added in a drop wise method and kept in a magnetic stirrer for 1 hour. Then the resulting white precipitated sample was carefully collected and washed several times with de-ionized water and then eventually with methanol. The filtered sample was then dried for 6-7 hours in a hot air oven and grained with mortar to a fine powder. In the case of silver-doped zinc oxide, $0.1 \mathrm{M}$ of silver nitrate added with zinc acetate and repeated above procedure of preparation. Glycerol is used as a capping agent in the preparation of silver-doped and undoped zinc oxide nanocrystallites.

\section{Structural Characterization}

Powder X-ray diffraction studies have been done using $\mathrm{Cu}-\mathrm{K} \alpha$ radiation $(\ddot{\mathrm{y}}=1.5406 \AA$ ) (D8 Advance Bruker diffractometer) to specify the sample's structural phase. Scanning electron microscope (SEM) using F E I Quanta FEG 200 - High-Resolution Scanning Electron Microscope was used to examine the surface morphology of the prepared nanocrystallites. The average size of the prepared samples was determined by the line broadening of the X-ray diffraction peaks corrected using Scherer's equation for instrumental broadening ${ }^{9}$.

\section{RESULTS AND DISCUSSION}

The Synthesized Nanocrystallites $\mathrm{ZnO}$ and $\mathrm{Ag}$ doped $\mathrm{ZnO}$ powder $\mathrm{XRD}$ pattern samples used glycerol as the capping agent are presented in Fig.-1a and $1 \mathrm{~b}$.

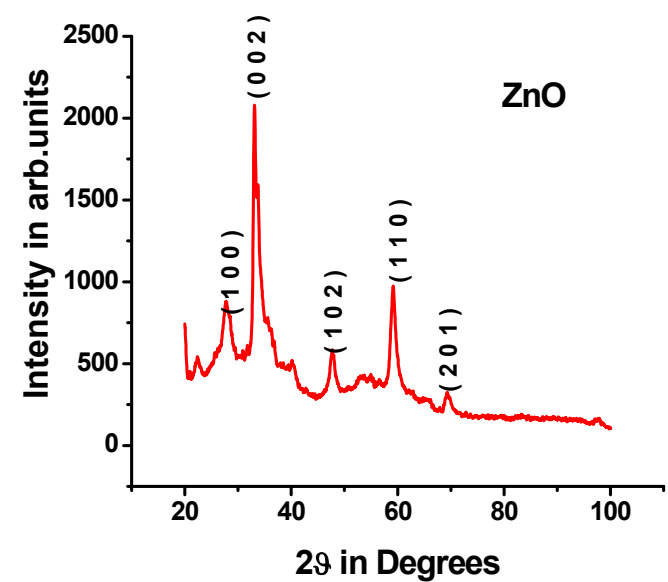

Fig.-1a: X-Ray Diffractogram of $\mathrm{ZnO}$

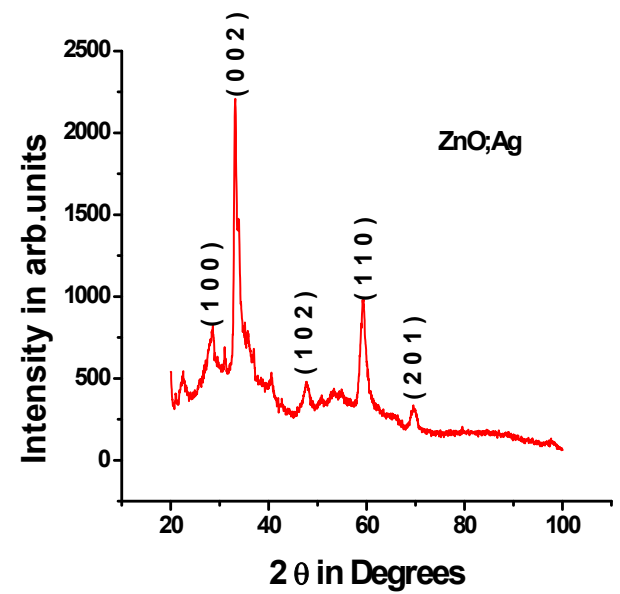

Fig.-1b: X-Ray Diffractogram of Ag: $\mathrm{ZnO}$

The XRD pattern shows five peaks at $2 \theta$ values equal to $31.223,33.507,47.747,56.102,69.309$ for $\mathrm{ZnO}$ sample and 31.028,33.492,47.735,57.003,69.646 for Ag:ZnO samples respectively. The peaks have been 
RASĀYAN J. Chem.

Vol. 13 | No. 1 |439 - 447| January - March | 2020

identified the indices $\left(\begin{array}{lll}1 & 0 & 0\end{array}\right)\left(\begin{array}{lll}0 & 0 & 2\end{array}\right)\left(\begin{array}{lll}1 & 0 & 2\end{array}\right)\left(\begin{array}{lll}1 & 1 & 0\end{array}\right)$ and (2 $\left.\begin{array}{ll}2 & 1\end{array}\right)$ respectively of the hexagonal structural phase of prepared samples (JCPDS No : 89 - 0511, 89 - 1397).

The present samples are prepared at normal room temperature whereas those from earlier studies ${ }^{9}$ require $\mathrm{d}$ significant reactant heating during Preparation. The average grain size of the samples was determined using the Debye- Scherrer Formula from the powder XRD data. ${ }^{10}$

Average Size, $D=K \lambda / \beta \cos \theta$

Where the factor $K=4 / 3$ accounts for the nanocrystallite quasi-spherical geometry, $\lambda$ is the wavelength of $\mathrm{X}$ - rays used, $\beta$ is Full width half maximum. The average size as $8 \mathrm{~nm}$ for $\mathrm{ZnO}$ and $18 \mathrm{~nm}$ for Ag: $\mathrm{ZnO}$ samples for the prepared samples. The volume fraction either decreases or increases depending on the nature of the dopant product ${ }^{11}$. $\mathrm{Ag}: \mathrm{ZnO}$ By increasing the volume fraction, $\mathrm{ZnO}$ has significantly increased its average size relative to $\mathrm{ZnO}$. $\mathrm{Ag}: \mathrm{ZnO}$ is found to have the effect of increasing the average particle size of $\mathrm{ZnO}$ in the present work.

The study of Scanning Electron Microscopy (SEM) was used to determine pure and Ag: $\mathrm{ZnO}$ morphological nanocrystallites.Figures- $2 \mathrm{a}$ and $2 \mathrm{~b}$ depict the representations of undoped $\mathrm{ZnO}$ and $\mathrm{Ag}$ : $\mathrm{ZnO}$.

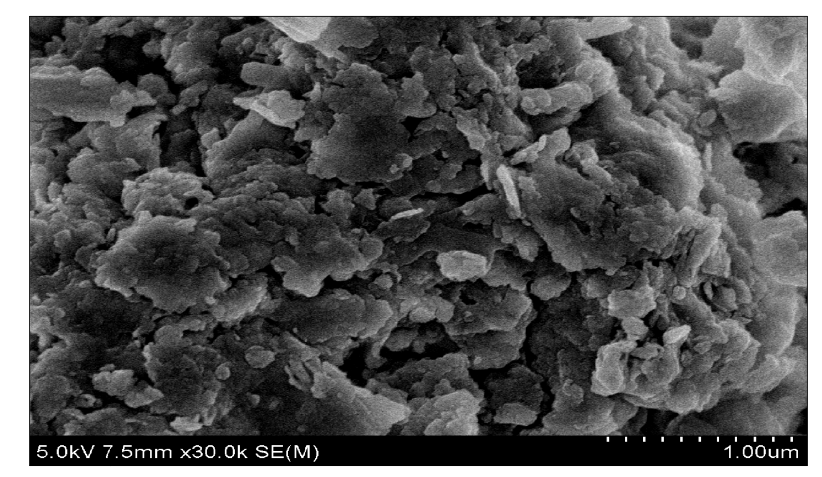

Fig.-2a: SEM Image of Pure $\mathrm{ZnO}$

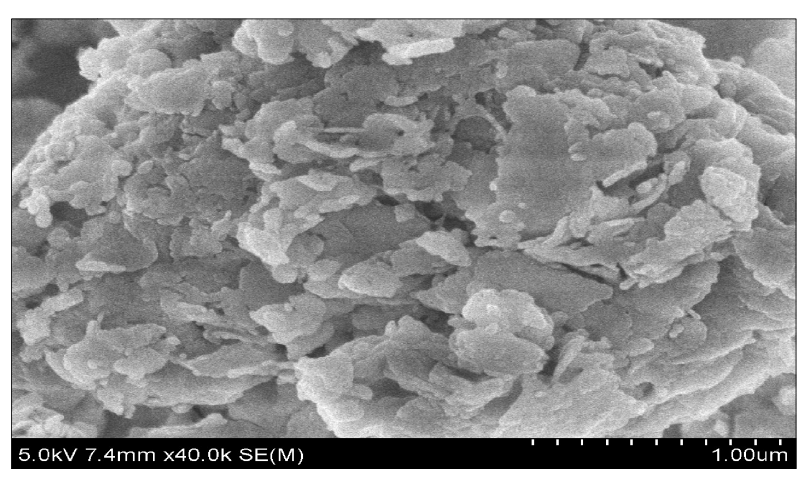

Fig.-2b: SEM Image of Ag: $\mathrm{ZnO}$

The particle size changes significantly with regard to doping agent addition. The morphology of undoped nanocrystallites is spherical with a diameter less than $20 \mathrm{~nm}$, according to Fig.-2a. Due to the accumulation of smaller particles, some larger particles may be attributed. It is clear from Fig.-2a that there is an aggregation of the smaller particles. Interestingly, the doped sample distribution is greater than the pure sample. Energy Dispersive X-Ray Analysis (EDX) examined the basic analysis of undoped and $\mathrm{Ag}$ : $\mathrm{ZnO}$ samples. Figure- $3 \mathrm{a}$ and $3 \mathrm{~b}$ illustrate the $\mathrm{EDX}$ analysis of undoped and $\mathrm{Ag}: \mathrm{ZnO}$ nanocrystallites respectively. Also described within the figures was the atomic percentage of all the elements. The 
RASĀYAN J. Chem.

Vol. 13 | No. 1 |439 - 447| January - March | 2020

occurrence of $\mathrm{Zn}$ and $\mathrm{O}$ elements was found in the EDX spectra of undoped $\mathrm{ZnO}$ nanocrystallites, similarly for $\mathrm{Ag}: \mathrm{ZnO}$, the presence of $\mathrm{Zn}, \mathrm{O}, \mathrm{Ag}$ was shown.

We calculated the average size (d) of our existing nanocrystalline samples using the Debye - Scherrer Formula Equation (1) in agreement with Borchert et.al. ${ }^{12}$ Earlier, Nanda et.al ${ }^{13}$ used the same method to accurately estimate the size of Semiconductor Nanocrystals. So in this present work we used the same formula to estimate the size of undoped $\mathrm{ZnO}$ and $\mathrm{Ag}: \mathrm{ZnO}$ nanocrystallites. The results show that $\mathrm{Ag}$ : $\mathrm{ZnO}$ significantly increases the average size of the crystallite and is attributed to the dopant Ag. For both the undoped $\mathrm{ZnO}$ and $\mathrm{Ag}$ : $\mathrm{ZnO}$ samples, the conditions of sample preparation are the same. Due to the volume fraction change, the size of a particle has increased due to the expression:

Volume Fraction $=1-(1-1 / \mathrm{d})^{2}$

Where $d$ is the size of the particle. This finding is in good agreement with that of Wang.et.al ${ }^{14}$ as previously mentioned. The average size of nanocrystallites and their $\mathrm{d}$ - spacing values collected from the powder XRD studies are shown in Table-1 for $\mathrm{ZnO}$ and $\mathrm{Ag}$ doped $\mathrm{ZnO}$ samples, respectively.

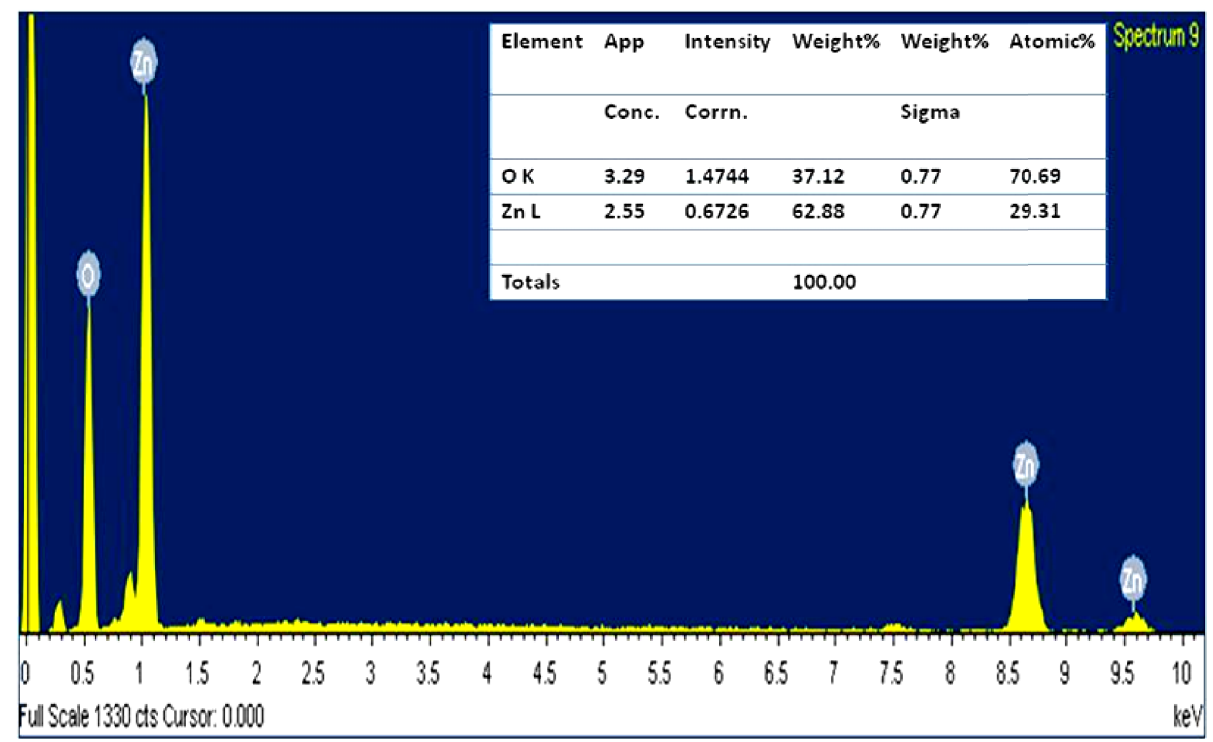

Fig.-3a: EDX Image of Pure ZnO

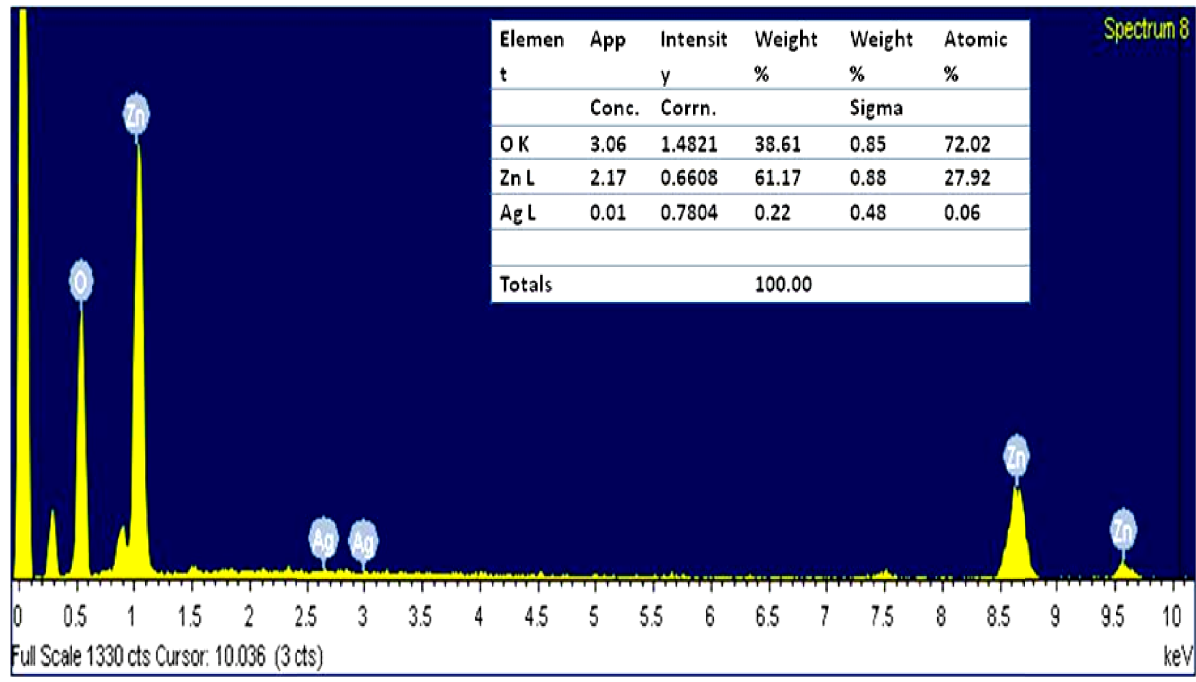

Fig.-3b: EDX Image of Ag: $\mathrm{ZnO}$ 
RASĀYAN J. Chem.

Vol. 13 | No. 1 |439 - 447| January - March | 2020

Table-1: Interplanar Spacing $\left(\mathrm{d}_{\mathrm{hkl}}\right)$, Average Grain Size(D) Bond Length (L), Lattice Parameter (LP), Volume Fraction, Atomic Packing Fraction (APF) and Lattice Strain Obtained by Powder XRD Studies for $\mathrm{ZnO}$ Nanocrystallites

\begin{tabular}{|c|c|c|c|c|c|c|c|c|c|}
\hline Sample & $2 \theta$ & h k 1 & $\mathrm{~d}(\AA)$ & $\begin{array}{l}\text { Average } \\
\text { Size } \\
(\mathrm{nm})\end{array}$ & $\begin{array}{l}\text { Bond Length } \\
(\mathrm{nm})\end{array}$ & Lattice Parameter & $\begin{array}{l}\text { Volume } \\
\text { Fraction } \\
(\AA ̊ 丿))^{3}\end{array}$ & $\begin{array}{l}\text { APF } \\
(\%)\end{array}$ & $\begin{array}{l}\text { Lattice } \\
\text { Strain }\end{array}$ \\
\hline $\mathrm{ZnO}$ & $\begin{array}{l}31.223 \\
33.507 \\
47.747 \\
56.102 \\
69.309\end{array}$ & $\begin{array}{l}100 \\
002 \\
102 \\
110 \\
201\end{array}$ & $\begin{array}{l}2.86 \\
2.67 \\
1.95 \\
1.65 \\
1.38\end{array}$ & 8 & 2.017603 & $\begin{array}{l}\mathrm{a}=3.31 \\
\mathrm{c}=5.34\end{array}$ & 50.56 & 74.95 & 0.0148 \\
\hline Ag: $\mathrm{ZnO}$ & $\begin{array}{l}31.028 \\
33.492 \\
47.735 \\
57.003 \\
69.646\end{array}$ & $\begin{array}{l}100 \\
002 \\
102 \\
110 \\
201\end{array}$ & $\begin{array}{l}2.87 \\
2.71 \\
1.97 \\
1.66 \\
1.38\end{array}$ & 18 & 4.1321 & $\begin{array}{l}\mathrm{a}=3.32 \\
\mathrm{c}=5.42\end{array}$ & 51.72 & 74.19 & 0.01375 \\
\hline
\end{tabular}

Using the Theoretical equation $\mathrm{d}_{\mathrm{hkl}}=1 /\left[\left(\mathrm{h}^{2}+\mathrm{k}^{2}+\mathrm{hk}\right) 4 / 3 \mathrm{a}^{2}+\mathrm{l}^{2} / \mathrm{c}^{2}\right]^{1 / 2}$

For the prepared samples d- spacing was calculated for $\mathrm{ZnO}$ and $\mathrm{Ag}$ : $\mathrm{ZnO}$ and results vary accordingly. It reveals the effect of doping in the prepared sample. The evaluated Bond length (L), Lattice Parameters (a $\&$ c) are given in table 1 , in which undoped $\mathrm{ZnO}$ gradually increases when dopant $\mathrm{Ag}$ is added. The bond length for prepared samples calculated using the formula: ${ }^{15}$

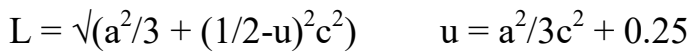

Where a \& c are the Lattice parameters, $\mathrm{u}$ is the positional parameter in the wurtzite structure.The Volume of the Unit cell has been calculated using the equation:

$$
\mathrm{V}=\sqrt{ } 3 / 2\left(\mathrm{a}^{2} \mathrm{c}\right)
$$

It has been found that the Volume of the Unit cell increases when the dopant is added which may be attributed to increase in the lattice parameters a and $\mathrm{c}$ and the values of the unit cell volume are given in Table 1. It reveals that Ag ions have moved to Zinc sites available in the structure. The lattice parameter. i.e., lattice constants a and c show a slightly increasing trend when $\mathrm{ZnO}$ is doped with Ag. The unit cell volume has risen with the higher doping rates, according to Vegard's law. ${ }^{16}$ Due to the larger ionic radius of Ag, the Lattice constants a and c for $\mathrm{ZnO}$ are in good agreement with Vegard's law. For Undoped $\mathrm{ZnO}$, the unit cell volume continues to decrease, whereas Ag: $\mathrm{ZnO}$ is increasing. The Atomic Packing Factor has been calculated using the formula:

$$
\mathrm{APF}=2 \pi \mathrm{a} / 3 \sqrt{3} \mathrm{c}
$$

Where a and $\mathrm{c}$ are the lattice parameters. The values of APF are listed in Table-1. The APF of bulk hexagonal $\mathrm{ZnO}$ materials is about $74 \%{ }^{17}$. In our case it is slightly increased for Undoped $\mathrm{ZnO}$, But for doped it is not much. Thus APF increases with decreasing Ag content, which describes that APF in nanocrystals is slightly greater than that of bulk materials. This is attributed to the size effect in the nanocrystalline samples.

Not only can peak expansion occur as a result of the size effect, but it can also be due to particle strain. Williamson-Hall's expression is one way to separate the stress due to particle size from the stress ${ }^{18}$ where $\eta$ is the strain in the particles which is a dimensionless quantity. The formula below is given for nonuniform strain. Average size $(\varepsilon)$ calculated using formula(6):

$$
\varepsilon=\beta / 4 \tan \theta
$$

The strain developed in powders was estimated using the above formula due to crystal imperfections and distortion (7). From the formula, it was confirmed that the peak width from crystallite size varies as $1 / \operatorname{Cos} \theta$ strain varies as $\tan \theta$. This fundamental concept was that the tiny crystallization size and 
RASĀYAN J. Chem.

Vol. 13 | No. 1 | 439 - 447| January - March | 2020

microstrain of each microstructural cause occur along with the widening of reflection. Thus from formula (7) we can write:

$$
\begin{array}{r}
\beta_{\mathrm{hkl}}=\beta_{\mathrm{s}}+\beta_{\mathrm{D}} \\
\beta_{\mathrm{hkl}}=[\mathrm{K} \lambda / \mathrm{D} \cos \theta]+4 \varepsilon \tan \theta
\end{array}
$$

rearranging eqn (9) gives:

$$
\beta_{\mathrm{hkl}}=\mathrm{K} \lambda / \mathrm{D}+4 \varepsilon \sin \theta
$$

Here eqn (10) stands for UDM where strain in all crystallographic directions is presumed to be uniform. $\beta \cos \theta$ was plotted with respect to $4 \sin \theta$ for the peaks of $\mathrm{ZnO}$ and $\mathrm{Ag}$ : $\mathrm{ZnO}$. From the slope and $\mathrm{y}-$ intercept of the fitted line, the strain and particle size are calculated. From the analysis of the lattice parameters, it was found that this strain could be due to the shrinking of the lattice. The UDM analysis for $\mathrm{ZnO}$ and $\mathrm{Ag}: \mathrm{ZnO}$ is shown in Fig. $-4 \mathrm{a}$ and $4 \mathrm{~b}$.

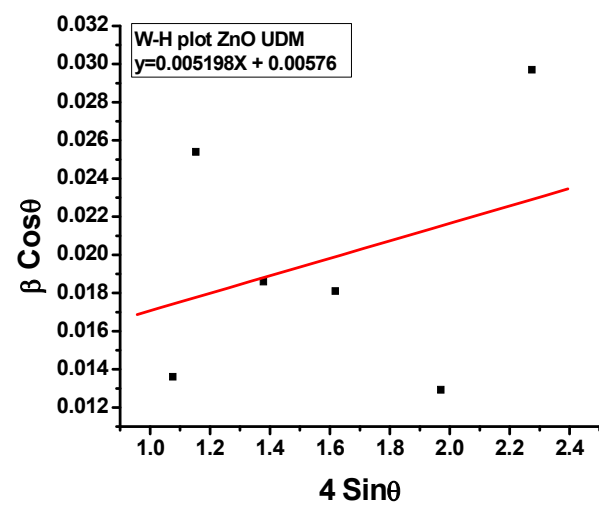

Fig.-4a: UDM Analysis of Pure $\mathrm{ZnO}$

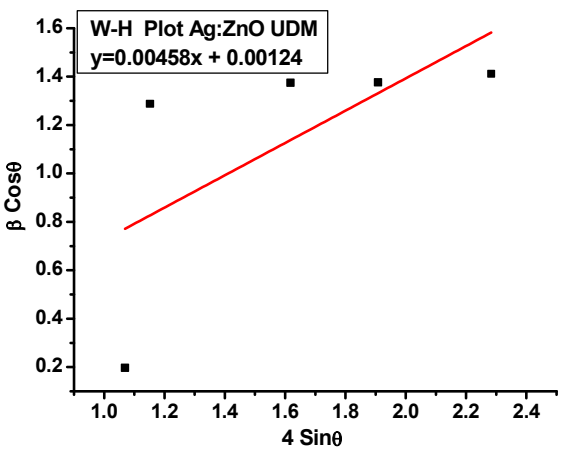

Fig.-4b: UDM Analysis of Pure ZnO

From Uniform stress Deformation Model (USDM) strain is calculated from the Hooke's law maintaining linear proportionality between stress and strain by $\sigma=\mathrm{Y} \varepsilon$, where $\sigma$ is the stress and Y is Young's modulus. Suppose a small strain to be present in the pure $\mathrm{ZnO}$ and $\mathrm{Ag}$ : $\mathrm{ZnO}$ Hooke's law can be used. The rule of this Hooke is true for a very small strain. Applying the Hooke's law approximation to eqn. (10) yields:

$$
\beta_{\mathrm{hkl}} \cos \theta=K \lambda / \mathrm{D}+4 \sigma \sin \theta / \mathrm{Y}_{\mathrm{hkl}}
$$

For a hexagonal crystal, Young's modulus is given by the following relation ${ }^{19}$ Equation (12) where $\mathrm{S}_{11}, \mathrm{~S}_{13}, \mathrm{~S}_{33}, \mathrm{~S}_{44}$ are the elastic compliances of $\mathrm{ZnO}$ with values of $7.858 \times 10^{-12},-2.206 \times 10^{-12}, 6.940 \times 10^{-12}$, $23.57 \times 10^{-12} \mathrm{~m}^{2} \mathrm{~N}^{-1}$ respectively. ${ }^{19}$

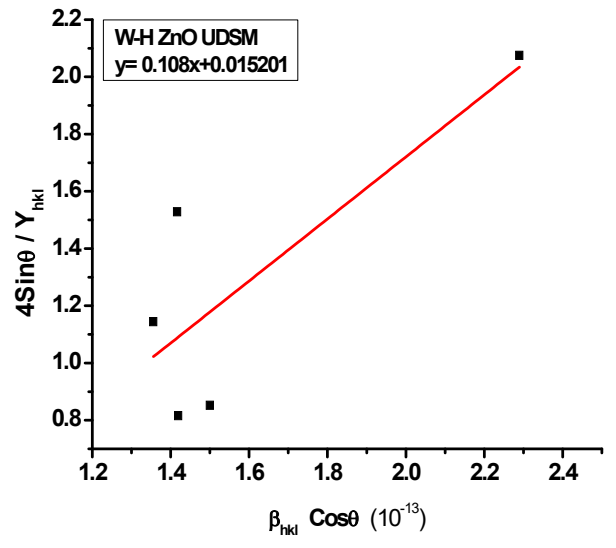

Fig.-5a: USDM Analysis of Pure ZnO

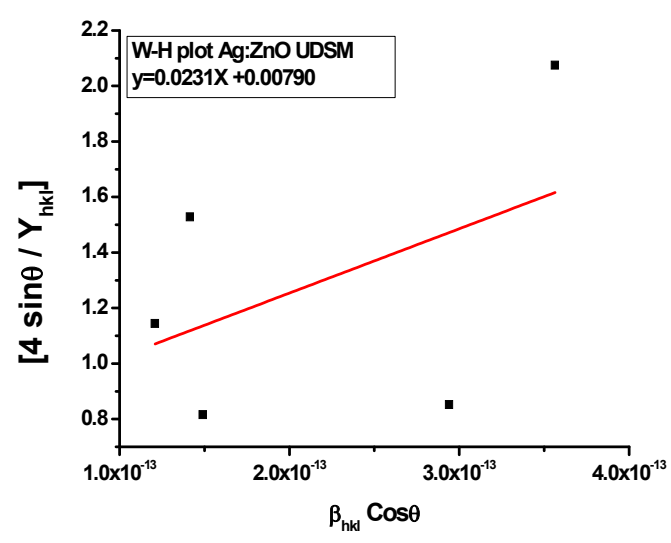

Fig.-5b: USDM Analysis of Ag: $\mathrm{ZnO}$ 
RASĀYAN J. Chem.

Vol. 13 | No. 1 | 439 - 447| January - March | 2020

Young's hexagonal $\mathrm{ZnO}$ module $\mathrm{Y}$ was estimated as approximately $0.130 \mathrm{Gpa} .4 \sin \theta / \mathrm{Y}_{\mathrm{hkl}}$ and $\beta \cos \theta$ were taken on $\mathrm{x}$-axis and $\mathrm{y}$-axis respectively. The USDM for $\mathrm{ZnO}$ with undoped and $\mathrm{Ag}$ Doped $\mathrm{ZnO}$ are shown in Figure $5 \mathrm{a}$ and $5 \mathrm{~b}$. The stress is calculated from the slope. ${ }^{20}$

$$
E(h k l)=\frac{\left[h^{2}+\frac{(h+2 k)^{2}}{3}+\left(\frac{a}{c} l\right)^{2}\right]^{2}}{s_{11}\left(h^{2}+\frac{(h+2 k)^{2}}{3}\right)^{2}+s_{33}\left(\frac{a}{c} l\right)^{4}+\left(2 s_{13}+s_{44}\right)\left(h^{2}+\frac{(h+2 k)^{2}}{3}\right)\left(\frac{a}{c} l\right)^{2}}
$$

The energy density of a crystal was calculated from a model called Uniform Deformation Energy Density Model (UDEDM). The energy density $u$ can be determined from $u=\left(\varepsilon^{2} Y_{\text {hkl }}\right) / 2$ using Hooke's law. We need to suggest from equation (13) that crystals are homogeneous and isotropic in nature. The equation (12) can be modified according to the energy and strain relation:

$$
\beta_{\mathrm{hkl}}=(\mathrm{K} \lambda / \mathrm{D})+\left(4 \sin \theta\left(2 \mathrm{u} / \mathrm{Y}_{\mathrm{hkl}}\right)^{1 / 2}\right)
$$

$4 \sin \theta\left(2 \mathrm{u} / \mathrm{Y}_{\mathrm{hkl}}\right)^{1 / 2}$ and $\beta_{\mathrm{hkl}} \cos \theta$ were taken on $\mathrm{x}$-axis and $\mathrm{y}$-axis respectively. The anisotropic energy density $u$ and the crystallite size $\mathrm{D}$ from the $\mathrm{Y}$-intercept of Figures $6 \mathrm{a}$ and $6 \mathrm{~b}$ were determined from the slope. We know that $\sigma=\mathrm{Y} \varepsilon$ and $u=\left(\varepsilon^{2} Y_{\mathrm{hkl}}\right) / 2$ the stress $\sigma$ was calculated as $u=\left(\varepsilon^{2} Y_{\mathrm{hkl}}\right) / 2$.

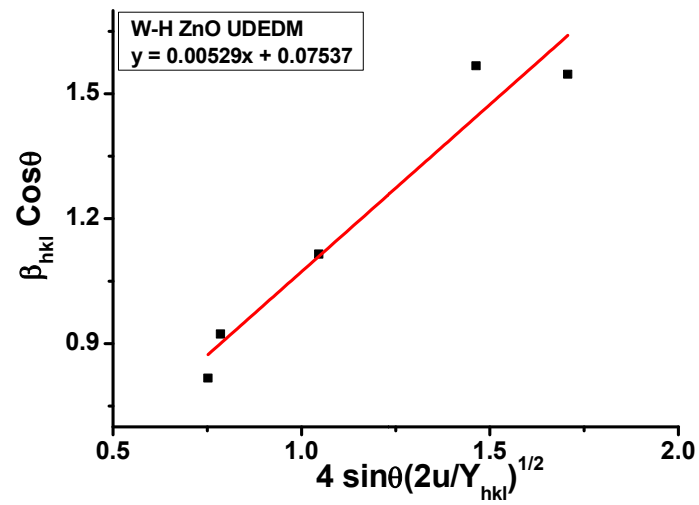

Fig.-6a: UDEDM Analysis of pure $\mathrm{ZnO}$

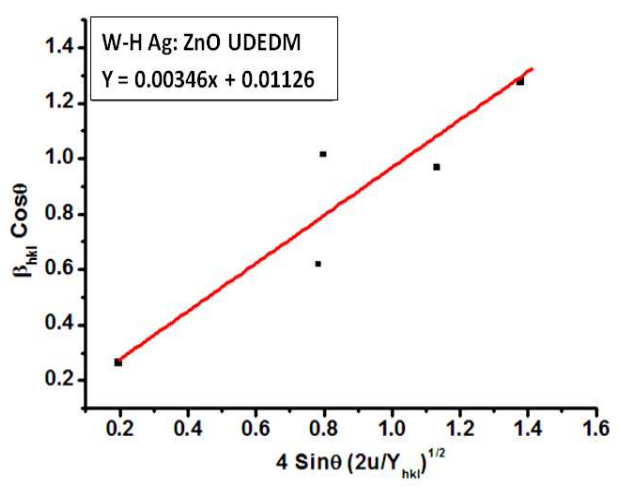

Fig.-6b: UDEDM Analysis of Ag: ZnO

It is possible to obtain the Size - Strain parameter from the size strain plot (SSP). This has an advantage that data from high angles are given less priority. In this calculation, it is assumed that the profile is represented by a Gaussian function with the "strain profile" and by the Lorentzian function with the crystallite size ${ }^{21}$. Hence we have:

$$
\left(\mathrm{d}_{\mathrm{hkl}} \beta_{\mathrm{hkl}} \operatorname{Cos} \theta\right)^{2}=\mathrm{K} / \mathrm{D}\left(\mathrm{d}^{2}{ }_{\mathrm{hk}} \beta_{\mathrm{hkl}} \cos \theta\right)+(\varepsilon / 2)^{2}
$$

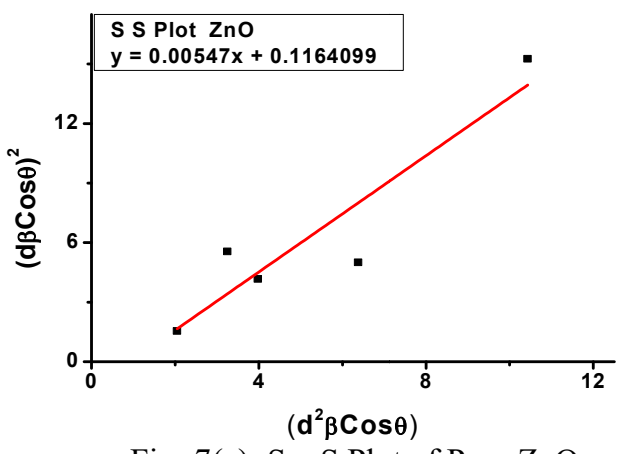

Fig.-7(a): S - S Plot of Pure ZnO

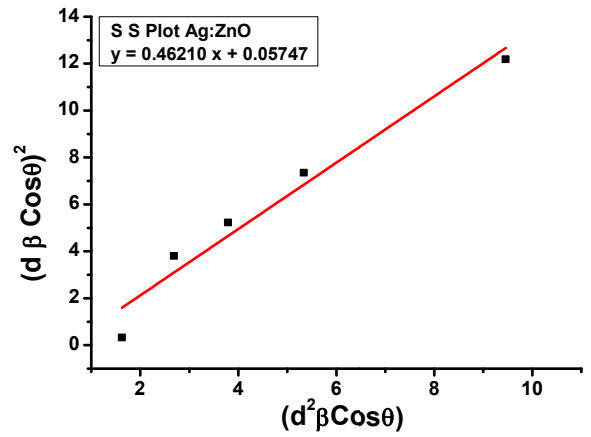

Fig.-7(b): S - S Plot of Ag: ZnO 
RASĀYAN J. Chem.

Vol. 13 | No. 1 | 439 - 447| January - March | 2020

Where $\mathrm{K}$ is a constant, shape of the particles for spherical particles. It is given as $4 / 3$. In Fig.-7a and $7 \mathrm{~b}$, $\mathrm{d}^{2}{ }_{\mathrm{hk}} \beta_{\mathrm{hkl}} \cos \theta$ and $\left(\mathrm{d}_{\mathrm{hkl}} \beta_{\mathrm{hkl}} \operatorname{Cos} \theta\right)^{2}$ were taken on the $\mathrm{x}$-axis and $\mathrm{y}$-axis respectively for all peaks of $\mathrm{ZnO}$ Nanoparticles with the Wurtzite hexagonal phase from $2 \theta=30^{\circ}$ to $2 \theta=70^{\circ}$. The particle size has been determined from the linear slope data and the y-intercept root gives the strain. Table- 2 summarizes the findings from the Scherrer method, W-H method, and SSP model.

Table-2: Geometric Parameters of $\mathrm{ZnO}$ and $\mathrm{Ag}$ : $\mathrm{ZnO}$

\begin{tabular}{|c|c|c|c|c|c|c|c|c|c|c|c|c|c|c|}
\hline \multirow[t]{3}{*}{ Sample } & \multirow{3}{*}{$\begin{array}{l}\text { D-S } \\
\text { Met } \\
\text { hod } \\
\text { D(nm) }\end{array}$} & \multicolumn{9}{|c|}{ W-H method } & \multicolumn{4}{|c|}{ S - S Plot } \\
\hline & & \multicolumn{2}{|l|}{ UDM } & \multicolumn{3}{|c|}{ USDM } & \multicolumn{4}{|c|}{ UDEDM } & & & & \\
\hline & & $\begin{array}{l}\mathrm{D} \\
(\mathrm{nm})\end{array}$ & $\varepsilon$ & $\begin{array}{l}\mathrm{D} \\
(\mathrm{nm})\end{array}$ & $\varepsilon$ & $\begin{array}{l}\Sigma \\
(\mathrm{Mpa})\end{array}$ & $\begin{array}{l}\mathrm{D} \\
(\mathrm{nm})\end{array}$ & $\begin{array}{l}\mathrm{U} \\
(\mathrm{kJm}) \\
\mathrm{e}^{-3}\end{array}$ & $\begin{array}{l}\Sigma \\
(\mathrm{Mpa})\end{array}$ & $\varepsilon$ & $\begin{array}{l}\mathrm{D} \\
(\mathrm{nm})\end{array}$ & $\begin{array}{l}\mathrm{U} \\
(\mathrm{kJm}) \\
\mathrm{e}^{-3}\end{array}$ & $\begin{array}{l}\Sigma \\
(\mathrm{Mpa})\end{array}$ & $\varepsilon$ \\
\hline $\mathrm{ZnO}$ & 8 & 11.1 & 0.005 & 9.12 & 0.108 & 166 & 12.3 & 81 & 198 & 0.005296 & 12.0 & 92 & 199 & 0.00547 \\
\hline $\begin{array}{l}\mathrm{Ag}: \\
\mathrm{ZnO}\end{array}$ & 18 & 24.07 & 0.004 & 18.01 & 0.023 & 128 & 18.3 & 53 & 144 & 0.00346 & 24.1 & 51 & 147 & 0.00482 \\
\hline
\end{tabular}

It was thus found that the average grain size of the undoped $\mathrm{ZnO}$ was $\sim 8 \mathrm{~nm}$. It is obvious from the table that when the particle size decreases strain the value of the lattice strain increases is inversely proportional to the average size. The average grain size of $\mathrm{Ag}$ : $\mathrm{ZnO}$ is $18 \mathrm{~nm}$. It was also revealed that $\mathrm{Ag}$ ions into $\mathrm{ZnO}$ increase the grain size. The size of the grain of the sample is increased by doping Ag. The grain size of this sample is slightly greater than the undoped $\mathrm{ZnO}$. We know the strain depends on the particle size, so $\mathrm{Ag}$ : $\mathrm{ZnO}$ strain is slightly lower than undoped $\mathrm{ZnO}$.

Concrete's porous structure is the general embodiment of porousness, distribution of Pore size, pore scale and pore geometry. Using $\mathrm{ZnO}$ nanoparticles to the concrete paste would make it easier to minimize the pore size. In terms of the multiple effects of pore size on concrete efficiency, a pore size of $<20 \mathrm{~nm}$ is defined as harmless, while $20-50 \mathrm{~nm}$ is considered to be less harmful and $50-200 \mathrm{~nm}$ is said to be harmful. Compressive strength, slump, restrained cracking of shrinkage and free shrinkage were investigated for the concrete. ${ }^{22}$

$\mathrm{ZnO}$ is majorly used in the four ranges of the pore structure of the concrete. They are (a) split tensile strength (b) flexural strength (c) setting time. It is more important in forming the cement mortars in the presence of $\mathrm{ZnO}$ and $\mathrm{Ag}: \mathrm{ZnO}$. An increase in the nanoparticles volume fraction resulted in a significant reduction in the setting time. The volume fraction is calculated using the equation (4) thus tabulated in Table-1 as Volume ( $\AA$ ) 3. The table shows that the hydration reaction rate of $\mathrm{ZnO}$ nanoparticles is lower than that of the cement itself. Though $\mathrm{Ag}: \mathrm{ZnO}$ has increased the speed of hydration reaction compared to cement due to the phenomenon that $\mathrm{Ag}$ : $\mathrm{ZnO}$ nanoparticles are distinguished by their specific surface effects, resulting in a large and rapid increase in the number of superfacial atoms Certain surface atoms are highly reactive and brittle, contributing to faster speed of reaction. Therefore, a holistic approach should be taken during the use of $\mathrm{Ag}$ : $\mathrm{ZnO}$ nanoparticles for the setting period of the cement paste. ${ }^{23} \mathrm{The}$ role of the nanoparticles in improving the concrete pore structure can be attributed to the fact that the nanoparticles are distributed uniformly in concrete and each particle is embedded in a very cube pattern and therefore the distance between nanoparticles is calculated.

\section{CONCLUSION}

We used chemical co-precipitation method to successfully synthesize samples. The XRD analysis verified that no secondary phase has been established, which means that $\mathrm{Ag}^{+}$successfully replaces the $\mathrm{Zn}^{2+}$ in $\mathrm{Ag}$ : $\mathrm{ZnO}$ and The characteristics of SEM+EDAX verified the hexagonal wurtzite structure and the constituents in the $\mathrm{ZnO}$ and $\mathrm{Ag}$ doped $\mathrm{ZnO}$ samples . Pure $\mathrm{ZnO}$ sample has the lowest grain size that is $\sim 8 \mathrm{~nm}$ and $\mathrm{Ag}: \mathrm{ZnO}$ has $\sim 18 \mathrm{~nm}$ respectively. The average strain depends on the particle size as the particle size increases the strain. Our material has a great impact on the porosity of the Concrete with its setting time based on volume fraction result. Cement could be beneficially substituted with $\mathrm{ZnO} / \mathrm{Ag}$ : $\mathrm{ZnO}$ nanoparticles. The pore structure and mechanical strength of the concrete was strengthened over the entire incorporation of nanoparticles. $\mathrm{ZnO}$ nanoparticles can also act as a filler to increase concrete density, resulting in a significant reduction in concrete porosity. 
RASĀYAN J. Chem.

Vol. 13 | No. 1 |439 - 447| January - March | 2020

\section{ACKNOWLEDGEMENT}

The Founder Chancellor-Doctral Committee is highly appreciated for awarding the scholar to conduct this research work.

\section{REFERENCES}

1. Mohammad Vaseem et.al., Metal Oxide Nanostructures and Their Applications, 5, 1(2010)

2. Surabhi Sivakumar, Putcha Venkateswarlu,Vanka Ranga Rao and Gollapalli Nageswara Rao, International Nano letters December, 3, 30(2013), DOI:10.1186/2228-5326-3-30.

3. Sidra Sabir, Muhammad Arshad, and Sunbal Khalil Chaudhari, The Scientific World Journal Volume 2014, Article 10 925494, 8 pages, DOI:10.1155/2014/925494

4. "Zinc Oxide (ZnO) Nanoparticles - Properties, Applications" AZoNano.com, 10 July 2013, www.azonano.com/article.aspx?ArticleID $=3348$

5. U. Koch, A. Fojtik, H. Weller, and A. Henglein, Chemical Physics Letters, 122, 507(2000), DOI: 10.1016/0009- 2614 (85)87255-9

6. D. Nivethita, S. Dharmar, International Journal of Science Technology and Engineering, 3, 25(2017)

7. R. Padmapriya, V.K. Bupesh Raja , V. Ganesh Kumar and J.Baalamurugan, Rasayan Journal of Chemistry,12(4),1744(2019), DOI:10.31788/RJC.2019.1245211

8. A. P. Alivistos, Journal of Physical Chemistry, 100, 13226(1996), DOI:10.1021/jp9535506

9. S. Chellammal, S. Sankar, Material Science in Semiconductor Processing, 13, 214(2010), DOI: $10.1088 / 1757-899 X / 310 / 1 / 012001$

10. B.Y. Geng, L.D. Zhang, G.Z. Wang, T. Xie, Y.G. Zhang, G.W. Meng (2004), Applied Physics Letters, 84, 2157(2004), DOI:10.1063/1.1687985 84, 2157

11. B.D. Cullity, Elements of X-ray Diffraction, $2^{\text {nd }}$ edn. Addison-Wesley, Reading, MA, (1978)

12. Zhong Lin Wang, Journal of Physics: Condensed Matter, 16, R829(2004), DOI:10.1088/09538984/16/25/Ro 1

13. H. Borchert, E.V. Shevchenko, A. Robert , I. Mekis, A. Kornowski, G. Grubel, H. Weller, Langmuir, 21,1931(2005), DOI:10.1021/1a0477183

14. J. Nanda, B.A. Kuruvilla, D.D. Sarma, Physical Review B, 59, 7473(1999), DOI: 10.1103/PhysRevB.59.7473

15. M. Wang, L. Sun, X. Fu, C. Liao, C. Yan, Solid State Communication, 115, 493(2000) DOI: 10.1016/j.stam.2005.03.006

16. G. Srinivasan, R. T. Rajendra Kumar, Journal of Sol-gel Technonlogy, 43, 171(2007),DOI: $10.1039 / \mathrm{C} 4 \mathrm{NJ} 02255 \mathrm{~F}$

17. V. Gandhi, R. Ganesan, H. H. A. Syedahamed, and M. Thaiyan, Journal of Physical Chemistry 118, 9715(2014), DOI:10.1021/jp411848t

18. A. Dhanalakshmi , B. Natarajan, V. Ramadas, A. Palanimurugan, and S. Thanikaikarasan, Pramana - Journal of Physics, 85, 57 (2016), DOI:10.1007/s12043-016-1248-0

19. J. Chauhan, N. Shrivastav, A. Dugaya and D. Pandey, Journal of Nanomedicine and Nanotechnology, 8(2), 429 (2017), DOI:10.4172/2157-7439.1000429

20. J. M. Zhang, Y. Zhang, K.-W. Xu, and V. Ji, State Communications, 139, 87(2006), DOI: $10.1016 / j . s s c .2006 .05 .026$

21. J. Zhang, Y. Zhang, K.W. Xu, V. Ji, Solid State Communications, 139, 87(2006), DOI: 10.1007/s10812-017-0497-0

22. J. F. Nye, (1985) Physical Properties of Crystals: Their Representation by Tensors and Matrices. Oxford, New York.

23. Mohammad Reza Aref and Saeed Rezaei-Zarchi, International Journal of Molecular Sciences, 13, 4340(2012), DOI:10.3390/ijms 13044340

24. S. Vignesh Kumar, R. Rajkumar and N. Umamaheswari, RASAYAN Journal of Chemistry, 2019,Vol.12(3), 1383-1389, DOI: 10.31788/RJC.2019.1235164

[RJC-5501/2019] 